\title{
A Study of Factors Influencing Sound Absorption Properties of Porous Materials
}

\author{
Martin Vašina ${ }^{1}$, Lumír Hružík ${ }^{1}$, Adam Bureček ${ }^{1}$, Miroslav Mahdal ${ }^{1}$, Katarína Monková ${ }^{2}$, Peter Pavol Monka ${ }^{2}$ \\ ${ }^{1}$ Faculty of Mechanical Engineering, VSB-Technical University of Ostrava, 17. listopadu 15/2172, 70833 Ostrava-Po- \\ ruba. Czech Republic. E-mail: martin.vasina@vsb.cz, lumir.hruzik@vsb.cz, adam.burecek@vsb.cz, miroslav.mah- \\ dal@vsb.cz. \\ ${ }^{2}$ Faculty of Manufacturing Technologies, Technical University of Košice, Štúrova 31, 08001 Prešov. Slovakia. E-mail: \\ katarina.monkova@tuke.sk, peter.pavol.monka@tuke.sk.
}

\begin{abstract}
A big accent is put on environmental protection at the present time. Noise belongs in general to negative factors of our environment. For this reason, it is necessary to perform suitable measures in order to eliminate noise. For example, it is possible to apply sound absorbers in order to damp noise. Materials with porous, spongy and fibrous structure belong generally to suitable materials in terms of noise damping. The aim of the paper is to investigate sound absorption properties of different types of porous materials. Frequency dependencies of the sound absorption coefficient over a frequency range of $150-6400 \mathrm{~Hz}$ were determined by the transfer function method using the acoustic impedance tube. Different factors, that have influence on sound absorption of the investigated porous materials, were studied in this paper. It can be concluded that sound absorption properties of the tested porous materials are significantly influenced by material structure and thickness, excitation frequency and air gap size behind the investigated samples.
\end{abstract}

Keywords: Sound Absorption Coefficient, Excitation Frequency, Air Gap, Thickness, Material Structure.

\section{Introduction}

Noise is occurring in many areas (e.g. means of transport, machinery equipment, aeronautics and military technics) and belongs to important factors of our environment [1]. It is defined as a displeasing and unwanted sound [2]. It belongs to one of the most encountered stressor to which mankind is exposed. Noise stress can lead to frustration, poor reading, impaired hearing and difficulty in problem solving activities [3]. For these reasons it is necessary to reduce the undesirable noise by appropriate means. There are different possibilities of the noise elimination [4 - 6], e.g. complete removal of a noise source, utilization of sound insulating panels and suitable sound absorbing (incl. multilayer) materials, application of protective equipment (i.e. ear plugs and headphones) etc.

The material ability to damp sound is characterized by the sound absorption coefficient $\alpha$ [7], which is expressed by the equation (1):

$$
\alpha=\frac{P_{a}}{P_{i}}=\frac{P_{i}-P_{r}}{P_{i}}[-],
$$

Where:

$\mathrm{P}_{\mathrm{a}}$...Absorbed acoustic power [W],

$\mathrm{P}_{\mathrm{i}}$... Incident acoustic power [W],

$\mathrm{P}_{\mathrm{r}}$...Reflected acoustic power [W].

The sound absorption coefficient of a given material depends in general on different factors, e.g. on material structure and thickness, excitation frequency of acoustic waves, air gap size behind the investigated material, surface shape, temperature etc. The effect of the excitation frequency on the sound absorption coefficient can be expressed by the noise reduction coefficient $N R C$, which is defined by the formula (2) as the average value of the material's sound absorption coefficients at frequencies of 250, 500, 1000 and $2000 \mathrm{~Hz}$ [8]:

$$
N R C=\frac{\alpha_{250}+\alpha_{500}+\alpha_{1000}+\alpha_{2000}}{4}[-] .
$$

This work is focused on different factors that have influence on sound damping properties of investigated porous materials.

\section{Experimental}

\subsection{Measurement methodology of sound absorption properties}

Sound absorption properties were experimentally measured at an ambient temperature of $22^{\circ} \mathrm{C}$ by means of the measuring equipment (see Fig. 1) that consists of BK 4206 two-microphone impedance tube, BK 3560-B-030 three-channel signal pulse multianalyzer and BK 2706 power amplifier (all from Brüel \& Kjær, Denmark). Furthermore, the measurements were performed for different sizes $a$ of air gap (ranging from 0 to $10 \mathrm{~cm}$ ) behind the tested material samples, as shown in Fig. 2.

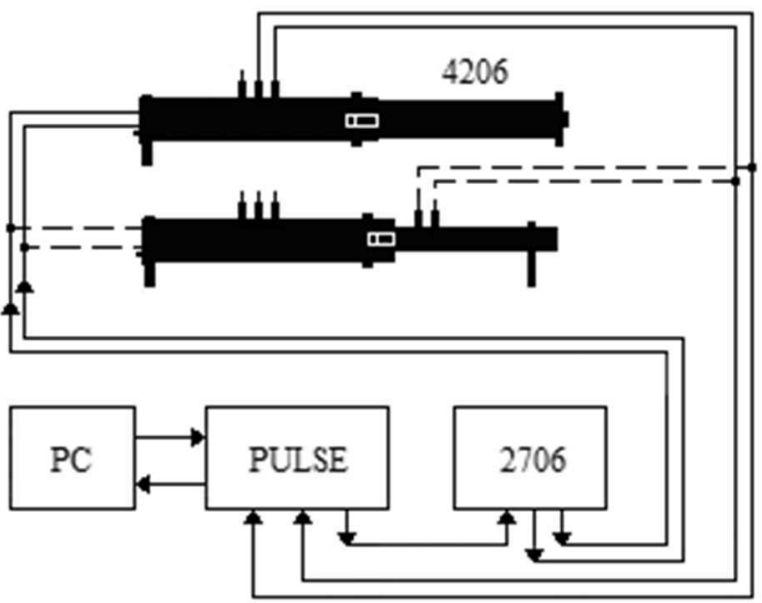

Fig. 1 Schematic representation of forced oscillation method 


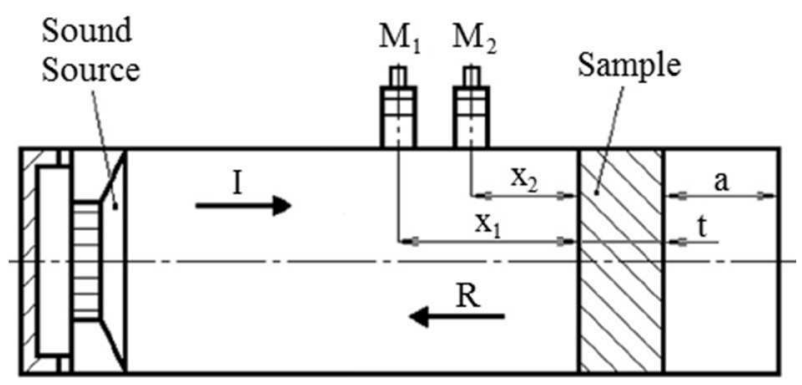

Fig. 2 Schematic of impedance measurement tube equipment (I-incident acoustic wave, $R$-reflected acoustic wave)

Frequency dependencies of the normal incidence sound absorption coefficient over a frequency range of $150-6400 \mathrm{~Hz}$ were measured by the transfer function method [9 - 11], which is based on the partially standing wave principle. In this case, the sound absorption coefficient $\alpha$ is expressed by the equation (3):

$$
\alpha=1-|r|^{2}[-]
$$

Where:

r... Normal incidence reflection factor [-].

The normal incidence factor, which consists of the real and imaginary part, is defined by the formula (4):

$$
r=\frac{H_{12}-H_{I}}{H_{R}-H_{12}} \cdot e^{2 k_{0} \cdot x_{1} i}[-],
$$

Where:

\begin{tabular}{|c|c|c|}
\hline Material designation & Material characterization & Density $\rho\left[\mathrm{kg} \cdot \mathrm{m}^{-3}\right]$ \\
\hline PUR_S1 & Polyurethane foam with small open pore volumes & 49 \\
\hline PUR_S2 & Polyurethane foam with small open pore volumes & 25 \\
\hline PUR M & Polyurethane foam with mean pore volumes & 31 \\
\hline PUR_L & Polyurethane foam with large open pore volumes & 29 \\
\hline PUR_REC & $\begin{array}{l}\text { Recycled polyurethane foam produced from waste polyurethane } \\
\text { foam of small open pore volumes and filled with binder }\end{array}$ & 83 \\
\hline RUB & Rubber of spongy structure with mean open cell volumes & 183 \\
\hline RUB_REC1 & $\begin{array}{l}\text { Recycled rubber produced from small waste rubber particles and } \\
\text { filled with binder }\end{array}$ & 675 \\
\hline RUB_REC2 & $\begin{array}{l}\text { Recycled rubber produced from large waste rubber particles and } \\
\text { filled with binder }\end{array}$ & 650 \\
\hline
\end{tabular}

Tab. 1 Specification of investigated materials

\section{Measured sound absorption characteristics}

This chapter deals with different factors that have influence on sound absorption properties of the investigated porous materials.

\subsection{Effect of material thickness}

The material thickness has generally a big influence on sound damping properties. The effect of the material thickness on sound absorption for the polyurethane foam PUR_S2 is shown in Fig. 3a. Similarly, the frequency dependencies of the sound absorption coefficient for different thicknesses of the recycled polyurethane foam PUR_REC are shown in Fig. $3 \mathrm{~b}$. It is evident that sound absorption properties are in general increasing with the increasing material thickness (see Fig. 3). For this reason,
$\mathrm{H}_{12}$...Complex acoustic transfer function [-],

$\mathrm{H}_{\mathrm{I}}$...Transfer function for the incident wave $[-]$,

$\mathrm{H}_{\mathrm{R}} \ldots$ Transfer function for the reflection wave $[-]$,

$\mathrm{k}_{0} \ldots$ Complex wave number $\left[\mathrm{m}^{-1}\right]$,

$\mathrm{x}_{1}$...Distance between the microphone $\mathrm{M}_{1}$ (see Fig. 2) and the tested material sample [m].

The transfer functions are expressed by the equations $(5) \div(7)$ :

$$
\begin{aligned}
H_{12}=\frac{p_{2}}{p_{1}} & =\frac{e^{k_{0} \cdot x_{2} i}+r \cdot e^{k_{0} \cdot x_{2} i}}{e^{k_{0} \cdot x_{1} i}+r \cdot e^{k_{0} \cdot x_{1} i}}[-], \\
H_{I} & =e^{-k_{0} \cdot\left(x_{1}-x_{2}\right) i}[-], \\
H_{R} & =e^{k_{0} \cdot\left(x_{1}-x_{2}\right) i}[-],
\end{aligned}
$$

Where:

$\mathrm{p}_{1}$...Complex acoustic pressure measured by the microphone $\mathrm{M}_{1}[\mathrm{~Pa}]$,

$\mathrm{p}_{2} \ldots$ Complex acoustic pressure measured by the microphone $\mathrm{M}_{2}[\mathrm{~Pa}]$,

$\mathrm{x}_{2}$...Distance between the microphone $\mathrm{M}_{2}$ (see Fig. 2) and the tested material sample [m].

\subsection{Investigated porous materials}

The experimental measurements of frequency dependencies of the sound absorption coefficient were performed for different material types of porous materials. The detailed designation, characterization and density of the investigated materials are shown in Tab. 1. the material thickness has a positive influence on sound damping. However, materials are acoustically effective from a certain excitation frequency $f_{m}$ [12] at which the sound absorption coefficient increases above $60 \%$ of its maximum value (i.e. $\alpha>0.6 \cdot \alpha_{\max }$ ). This excitation frequency can be approximately expressed by the formula (8):

$$
f_{m}=\frac{c}{10 \cdot t}[H z]
$$

Where:

c... Speed of sound in air $\left[\mathrm{m} \cdot \mathrm{s}^{-1}\right]$,

t... Thickness of the tested sample [m].

The minimum material thickness $t_{\min }$, that is necessary for the acoustically effective damping from the required 
frequency $f_{m}$, can be determined from the Eq. (8) as follows:

$$
t_{\min }=\frac{c}{10 \cdot f_{m}}[m]
$$

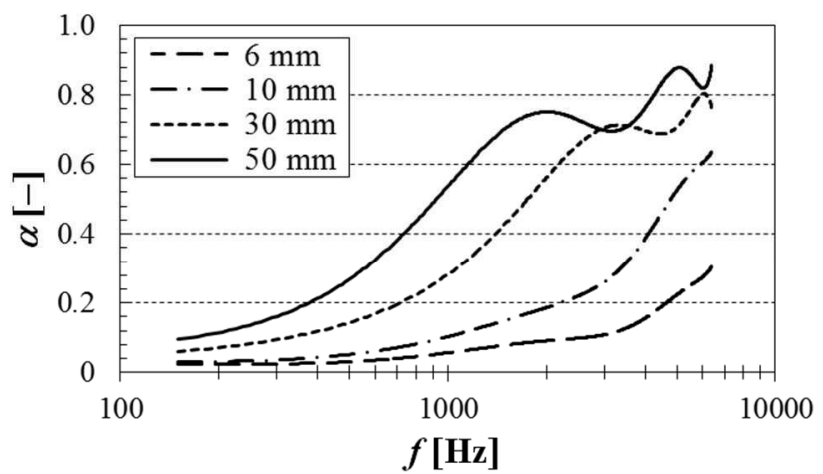

a)

$f[\mathrm{~Hz}]$
As mentioned above, better sound absorption properties are generally obtained at higher thicknesses of the investigated materials. Nevertheless, the increasing material thickness leads to higher financial costs. A better solution is to place a thin porous material at a certain distance $a$ from the fixed wall (see Fig. 2).

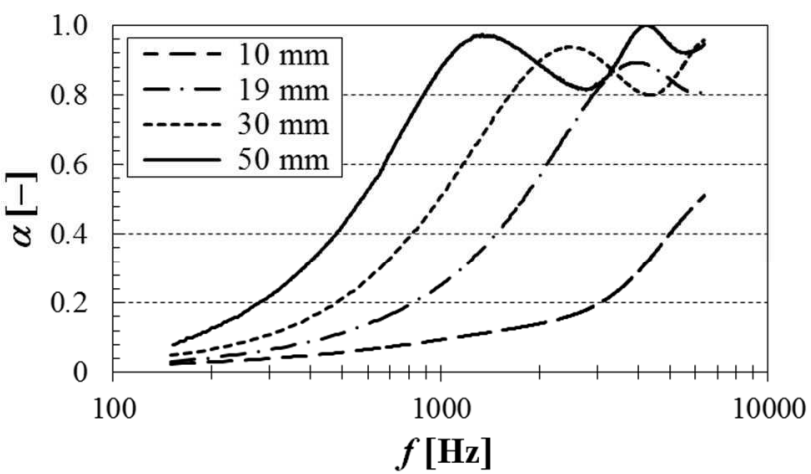

b)

Fig. 3 Frequency dependencies of the sound absorption coefficient for the polyurethane foam PUR_S2 (a) and the recycled polyurethane foam PUR_REC (b) without the air gap $(a=0 \mathrm{~cm})$ behind the tested material samples

\subsection{Effect of air gap size}

Sound absorption properties of porous materials are also influenced by the air gap size $a$ (see Fig. 2) between the tested porous samples and the fixed wall, which is characterized by ideal sound reflection (i.e. $\alpha_{\text {wall }}=0$ ) of incident acoustic wave. The effect of the air gap size on frequency dependencies of the sound absorption coefficient for the polyurethane foam PUR_S1 is shown in Fig. 4a. Similarly, the frequency dependencies of the sound absorption coefficient at different air gap sizes for the recycled rubber RUB_REC2 are shown in Fig. 4b. It is evident that the air gap size has a positive effect on sound absorption (mainly at low excitation frequencies). The transformation of acoustic energy into heat is connected with acoustic velocity [12], which is zero on the wall behind the tested material sample. The acoustic velocity increases with the increasing distance from the wall. The first maximum of the acoustic velocity is obtained at the distance $l=\lambda / 4$ (i.e. antinode of the standing waves), where $\lambda$ is the wave length in the given environment.

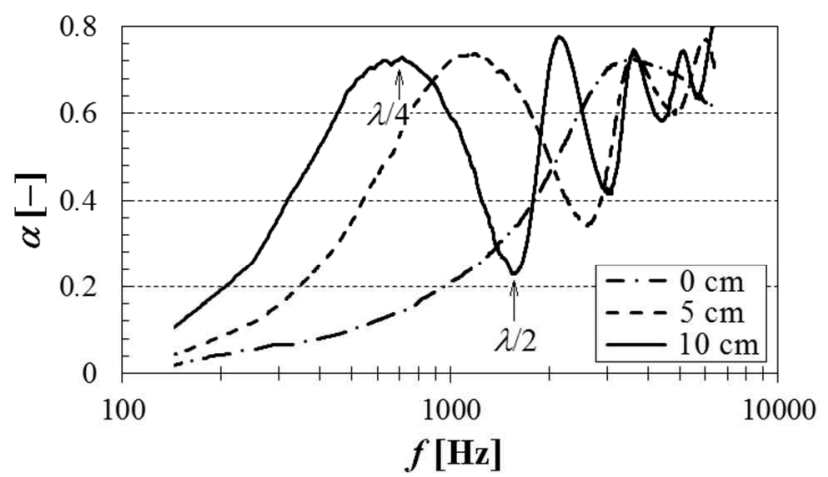

a)

Fig. 4 Frequency dependencies of the sound absorption coefficient for the polyurethane foam PUR_S1 (a) of the thickness $t=22 \mathrm{~mm}$ and the recycled polyurethane foam $R U B \_R E C 2$ (b) of the thickness $t=30 \mathrm{~mm}$ at different air gap sizes behind the tested material samples
Therefore, it is suitable to locate a thin material sample at the same distance (i.e. $l=\lambda / 4=a+t / 2$ ) in order to transform the acoustic energy into heat. Then the maximum values of the sound absorption coefficient are generally obtained in antinodes of the standing waves at excitation frequencies that are expressed by the equation (10):

$$
f=\frac{c \cdot(2 n+1)}{4 \cdot l}[H z],
$$

Where:

$\mathrm{n} . .$. Integer $(\mathrm{n}=0,1,2)[-]$.

Similarly, the minimum values of the sound absorption coefficient are generally obtained in nodes of the standing waves at excitation frequencies that are given by the formula (11):

$$
f=\frac{c \cdot n}{2 \cdot l}[H z] .
$$

It is evident from the above-mentioned reasons that the frequency dependencies of the sound absorption coefficient are periodic (see Fig. 4).

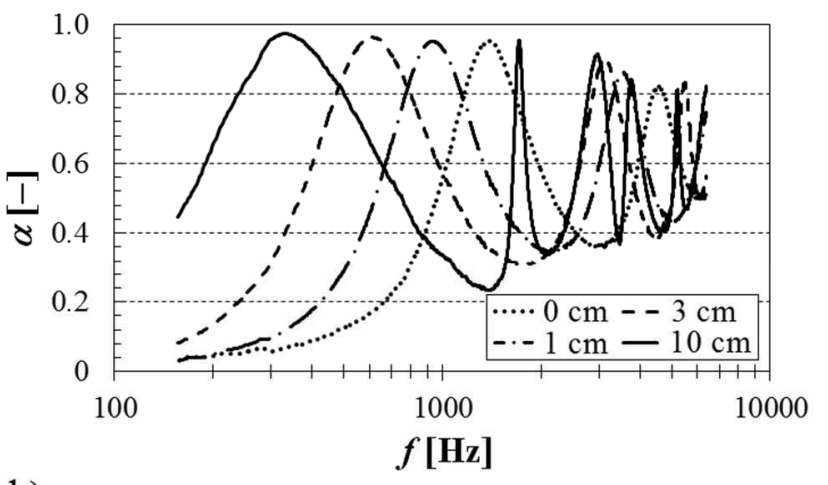

b) 


\subsection{Effect of material structure}

Sound absorption properties of porous materials are significantly influenced by their structure, e.g. by number, size and form of pores, size and form of particles, binder type, its concentration etc. The structure effect of the investigated porous polyurethane foams (with the thickness $t=5 \mathrm{~cm}$ and the air gap size $a=3 \mathrm{~cm}$ behind the samples) on their sound absorption properties is shown in Fig. 5a. It is evident from this comparison that better sound absorption properties were generally found for polyurethane foam with smaller pore sizes and higher density. This fact is observed mainly at lower excitation frequencies (i.e. at $f<1 \mathrm{kHz}$ ). The influence of the material structure for the recycled materials and the spongy

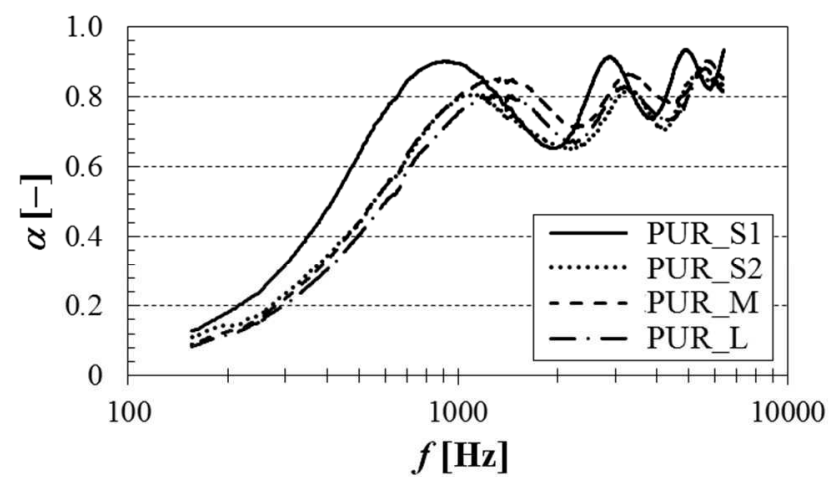

a)

Fig. 5 Frequency dependencies of the sound absorption coefficient for: (a) polyurethane foams of the thickness $t=50$ $\mathrm{mm}$ with the air gap size $a=3 \mathrm{~cm}$, (b) recycled rubber materials and spongy rubber of the thickness $t \cong 20 \mathrm{~mm}$ with the air gap size $a=1 \mathrm{~cm}$

\subsection{Effect of excitation frequency}

The excitation frequency has a big influence on sound absorption properties of a given material sample too. It is evident from the measured results (see Fig. 3 and Fig. 5) that better sound damping properties are generally obtained at higher excitation frequencies. In the case of low excitation frequencies, it is possible to increase values of the sound absorption coefficient of porous materials by means of the air gap behind the investigated material samples (see Fig. 4). Furthermore, the effect of the excitation frequency can be expressed by means of the noise reduction coefficient $N R C$ from the Eq. 2.

The dependence of the noise reduction coefficient on the thickness of several materials with different air gap sizes behind the tested samples is shown in Fig. 6. It is visible that the noise reduction coefficient is generally increasing with the increasing material thickness. It can be also concluded that higher values of the noise reduction coefficient (i.e. better sound absorption properties) were obtained for the polyurethane foam with small open pore volumes with higher material density (i.e. PUR S1 type) compared to the similarly structured sample of lower material density (i.e. PUR_S2 type). This fact is in a good agreement with the frequency dependence of the sound absorption coefficient of these polyurethane foams (see Fig. 5a).

It was also verified that the air gap has a positive in- rubber (with the thickness $t \cong 2 \mathrm{~cm}$ and the air gap size $a$ $=1 \mathrm{~cm}$ behind the samples) on their ability to damp sound is shown in Fig. 5b. It is visible from this comparison that sound damping properties depend mainly on the excitation frequency. In the case of low excitation frequencies (i.e. at $f<900 \mathrm{~Hz}$ ), better sound absorption was obtained for the spongy rubber and the recycled rubber material with small rubber particles. On the contrary, the tested recycled polyurethane foam is more suitable for sound damping at higher excitation frequencies (i.e. at $f>1050$ $\mathrm{Hz}$ ). The investigated recycled rubber material with large rubber particles is the most suitable in terms of sound absorption only in a very narrow frequency range (from 0.90 to $1.05 \mathrm{kHz}$ ) from the compared materials (see Fig. $5 \mathrm{~b}$ ).

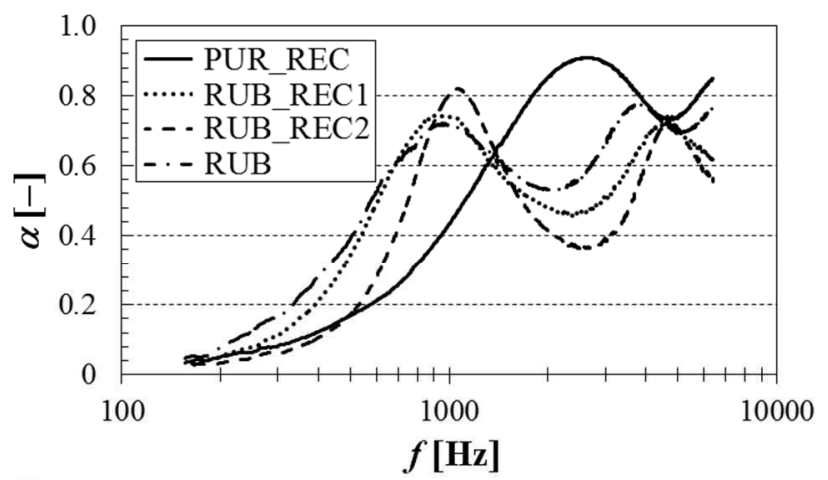

b) fluence on sound damping. It is evident from the comparison (see Fig. 6), that higher values of the noise reduction coefficient were obtained for the recycled polyurethane foam with the air gap (i.e. $a=10 \mathrm{~cm}$ ) compared to the same material sample, which was located inside the measuring impedance tube without the air gap (i.e. $a=0 \mathrm{~cm}$ ).

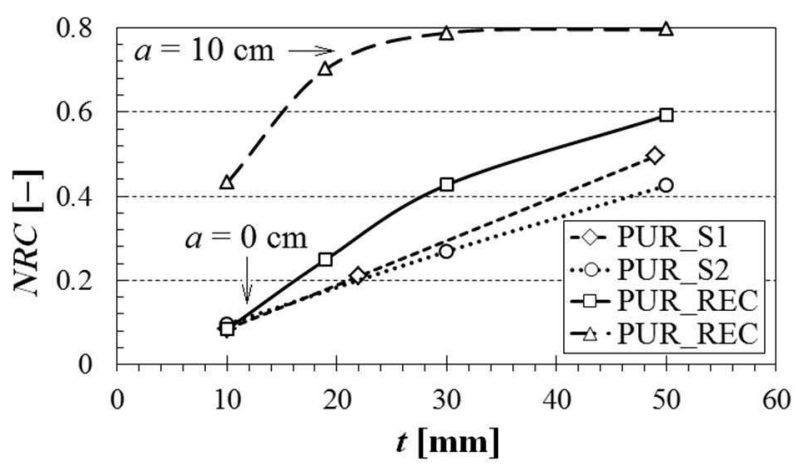

Fig. 6 Dependence of noise reduction coefficient on thickness for different material types and air gap sizes

\section{Conclusion}

This purpose of this paper was to examine different factors that have an influence on sound absorption of porous materials. The research consisted in experimental measurements of frequency dependencies of the sound absorption coefficient by means of the transfer function 
method. The measurements were performed on different types of porous materials, e.g. on polyurethane foam, spongy rubber and recycled waste materials. It was found in this study that sound absorption properties of porous materials are influenced by many factors. It can be concluded that better sound absorption properties of the investigated materials were generally obtained at higher excitation frequencies, higher material thicknesses and for materials with small open pore volumes. However, the application of thicker materials is economically disadvantageous. For this reason, it is possible to apply sound damping systems with air gap in order to increase sound absorption of materials with porous structures. In this case, sound absorption coefficient values are generally increasing with the increasing air space size. This phenomenon is evident especially at low excitation frequencies of acoustic waves. Great emphasis is also placed on environmental protection at the present time. It was found in this work that the tested recycled waste materials exhibited relatively good sound insulation properties in some cases. This is one of the possible applications of these materials in practice.

\section{Acknowledgements}

This work was supported by the European Regional Development Fund in the Research Centre of Advanced Mechatronic Systems project, project number CZ.02.1.01/0.0/0.0/16_019/0000867 within the Operational Programme Research, Development and Education and by the Ministry of Education of $S R$ with the project KEGA 007TUKE-4/2018.

\section{References}

[1] KOVÁČIKOVÁ, P., VAvRO, J., DUBEC, A. (2018). Measuring of vibration-damping properties of iron cast. In: Manufacturing Technology. Vol. 18, No. 1, pp. 57-59. Elsevier. Netherlands.

[2] GOINES, L., HAGLER, L. (2007). Noise pollution: A modern plague. In: Southern Medical Journal. Vol. 100, No. 3, pp. 287-294. Lippincott Williams \& Wilkins. USA.

[3] NAQVI, F., HAIDER, S., BATOOL, Z., PERVEEN, T., HALEEM, D. J. (2012). The Impact Sub-chronic exposure to noise affects locomotor activity and produces anxiogenic and depressive like behavior in rats. In: Pharmacological Reports. Vol. 64, No. 1, pp. 64-69. Polish Academy of Sciences, Institute of Pharmacology. Poland.
[4] KMEC, J., KUCERKA, D., GOMBAR, M., KARKOVA, M., VAGASKA, A. (2016). Measurement of noise during the process of cutting materials by Water Jet. In: Manufacturing Technology. Vol. 16, No. 2, pp. 354-360. Elsevier. Netherlands.

[5] SUCHÁNEK, A., LOULOVÁ, M., HARUŠINEC, J., STRÁŽOVEC, P. (2018). Use of infrared thermography under laboratory conditions. In: Manufacturing Technology. Vol. 18, No. 3, pp. 518-522. Elsevier. Netherlands.

[6] KORMANÍKOVÁ, E., KOTRASOVÁ, K. (2017). Buckling and free vibration analysis of sandwich plate. In: International Journal of Mechanics. Vol. 11, pp. 299-304. Nord Atlantic University Union. Canada.

[7] SGARD, F., CASTEL, F., ATAlla, N. (2011). Use of a hybrid adaptive finite element/modal approach to assess the sound absorption of porous materials with meso-heterogeneities. In: Applied Acoustics. Vol. 72, No. 4, pp. 157-168. Elsevier. England.

[8] NA, Y., LANCASTER, J., CASALI, J., CHO, G. (2007). Sound absorption coefficients of micro-fiber fabrics. In: Textile Research Journal. Vol. 77, No. 5, pp. 330-335. Sage Publications Ltd. England.

[9] ISO 10534-2:1998 Acoustics - Determination of sound absorption coefficient and impedance in impedance tubes - Part 2: Transfer function method.

[10] LEE, Y. E., JOO, C. W. (2004). Sound absorption properties of thermally bonded nonwovens based on composing fibers and production parameters. In: Journal of Applied Polymer Science. Vol. 92, No. 4, pp. 2295-2302. John Wiley \& Sons. USA.

[11] LIU, Y., JACOBSEN, F. (2005). Measurement of absorption with $\mathrm{p}-\mathrm{u}$ sound intensity probe in an impedance tube (L). In: Journal of the Acoustical Society of America. Vol. 118, No. 4, pp. $2117-$ 2120. Acoustical Society of America. USA.

[12] NĚMEC, J., RANSDORF, J., ŠNÉDRLE, M. (1970). Hluk a jeho snižování v technické praxi / Noise and its elimination in engineering practice. 340 p. SNTL, Prague (in Czech). 